\title{
L'Al œuvre en faveur de la réinsertion professionnelle: il faut faire preuve de bonne volonté en terrain difficile
}

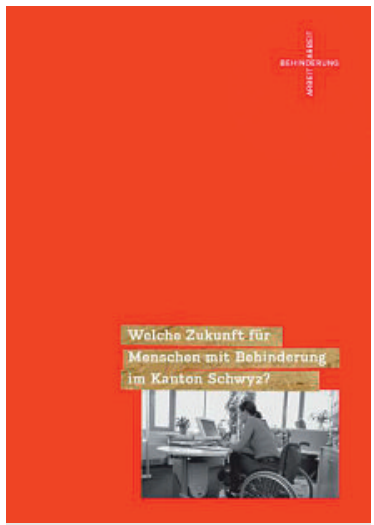

L'exposition itinérante pour les 50 ans de I'Al, organisée par la Conférence des offices $\mathrm{Al}$, a entamé un tour de Suisse. Elle sera présentée jusqu'à fin 2010 principalement dans des salons et des foires et elle sera enrichie par des programmes-cadres d'organisations telles que Luga (Lucerne), Ostschweizer Personaltag (St-Gall), Handicap sur la Fête (Delémont), GEWA (Seewen), HESO (Soleure). Des renseignements détaillés figurent sous www.ivsk.ch.

Voir également à ce sujet l'article à la page 559 .

\section{* PD Dr rer. soc} Eberhard Wolff est licencié en science culturelles, historien de la médecine et membre de la rédaction Histoire de la médecine du Bulletin des médecins suisses.
Quand il s'agit de l'assurance-invalidité (AI), on évoquait ces dernières années d'abord le nombre de zéros constituant son déficit, soit quatorze milliards de francs. L'accroissement de la dette s'est élevé à un milliard, rien qu'en 2009. L'assainissement a démarré et les électeurs ont accepté à une faible majorité l'augmentation temporaire de la TVA. L'AI elle-même s'est engagée à prendre des mesures. Mais elle se trouve dans un dilemme. Si elle ne referme le robinet des dépenses qu'avec prudence, le déficit restera trop élevé, et si elle le referme trop fort, on lui reprochera de transférer des personnes handicapées dans d'autres œuvres sociales ou de les exclure de toute aide alors qu'elles sont dans le besoin. les foires et les salons. L'AI a calculé qu'il manquait 192000 places de travail pour ses clients. Les incitatifs financiers ne semblent pas suffire pour insérer professionnellement des personnes dotées de capacités et souffrant d'un handicap. Il faut abolir les préjugés. De nombreuses compétences sont reléguées au second plan parce qu'on voit avant tout le handicap. Si l'on compare les coûts générés, dans une entreprise, par l'absence des collaborateurs dits valides pour cause de maladie et autres motifs, les différences ne sont plus si importantes.

L'exposition présente par exemple l'intégration d'une infirmière qui est engagée, après une grave dépression, dans le service d'un hôtel à caractère social

\section{«Les incitatifs financiers ne semblent pas suffire pour insérer professionnellement des personnes dotées de capacités et souffrant d'un handicap"}

Pour diminuer la pression de ce serrement de vis, l'AI mène une réflexion approfondie, plus précisément par le biais de la Conférence des offices AI (COAI), qui en est l'organisation faîtière. Celle-ci revient aux anciennes vertus en intensifiant la réinsertion professionnelle des «personnes atteintes dans leur santé». Cette mesure coûte moins cher à l'AI et aux contribuables tout en étant bénéfique pour ses clients. En Suisse, les personnes qui ont un emploi profitent souvent mieux de la vie.

L'AI escompte en outre un effet secondaire, celui de rétablir son image, passablement égratignée, et d'élargir l'horizon des débats sociopolitiques où l'on n'entend que trop souvent les termes de «tromperie» et de «détective». Dans ce contexte, la COAI agit plus délicatement que ses collègues de l'Office fédéral qui avaient mené une campagne d'affichage provocatrice et contestée. Vous vous en souvenez: «Les personnes handicapées ne nous coûtent que de l'argent ...».

Ce jubilé arrive fort à propos. L'exposition itinérante pour les 50 ans de l'AI va faire un tour de Suisse (cf. encadré). Le dialogue sera entamé avec la population et les employeurs potentiels essentiellement dans et qui reprend pied grâce à un travail exerçant une pression moins forte. Ou cet homme présentant des difficultés d'élocution et qui a trouvé un emploi dans une menuiserie compréhensive. Ces engagements peuvent fonctionner, aussi dans les entreprises à but lucratif. «Malgré tout, il existe encore 95000 entreprises qui seraient prêtes à engager des personnes atteintes dans leur santé mais qui ne le font quand même pas», souligne Stefan Ritler, ancien président de la COAI et, dès le mois de mai, chef de la section AI à l'Office fédéral des assurances sociales. Au contraire des pays comme la République fédérale d'Allemagne, la Suisse ne connaît aucune mesure contraignante pour les employeurs.

Trouver des emplois pour les personnes atteintes d'un handicap est une chose délicate en temps de crise. Ainsi que le journal «Tagesanzeiger» l'annonçait il y a peu, les différents offices sociaux se livrent une concurrence accrue dans la lutte pour des emplois «créneaux» (6. 1.2010). Lorsqu'il devient plus restreint, le marché du travail fait appel à l'innovation.

Eberhard Wolff* 